\title{
ANALISIS KEAUSAN LINE CONTACT MENGGUNAKAN PERMODELAN GLOBAL INCREMENTAL WEAR MODEL
}

\author{
Asdiar Surya Kurniawan*, Imam Syafa'at, Darmanto \\ Jurusan Teknik Mesin, Fakultas Teknik, Universitas Wahid Hasyim \\ Jl. Menoreh Tengah X/22, Sampangan, Semarang 50236. \\ "Email: asdiar.kurniawan@gmail.com
}

\begin{abstract}
Abstrak
Keausan merupakan fenomena tribologi yang terjadi pada setiap peralatan akibat kontak mekanik antara dua komponen. Dalam kurun waktu yang lama keausan ini akan menimbulkan kerusakan pada peralatan. Untuk meningkatkan keandalan dan efisiensi peralatan, maka fenomena keausan ini perlu dikaji lebih lanjut. Penelitian ini bertujuan menghitung kedalaman aus dan volume aus sebuah pin berbentuk silinder pendekatan line contact menggunakan tribometer pin-on-disc. Variasi yang dilakukan adalah pembebanan yaitu sebesar $6 \mathrm{~N}, 8 \mathrm{~N}$, dan $10 \mathrm{~N}$. Pengujian keausan dilakukan pada keadaan tanpa pelumas. Hasil eksperimen kemudian dibandingkan dengan metode analitik GIWM (Global Incremental Wear Model). Hasil penelitian memperlihatkan bahwa eksperimen tribometer pin-on-disc dan GIWM sama-sama berbanding lurus dengan pembebanan. Pada beban 10 $N$ dengan jarak sliding 904,32 $m$ memiliki kedalaman aus 2,46096E-05 $m$ dan volume keausan 1,62778E-08 $\mathrm{m}^{3}$. Pada beban $6 \mathrm{~N}$ pada jarak sliding yang sama memiliki kedalaman aus 1,75067E-05 m dan volume aus 9,76666E-09 $\mathrm{m}^{3}$. Semakin bertambah pembebanan dan jarak sliding maka nilai keausan semakin bertambah.
\end{abstract}

Kata kunci: GIWM, keausan, line contact, pin-on-disc, tribometer.

\section{PENDAHULUAN}

Salah satu fenomena yang terjadi dalam bidang permesinan adalah fenomena kontak antar komponen. Kontak yang terjadi antar komponen bisa berupa static contact, rolling contact, atau sliding contact. Kontak mekanik (contact mechanic) merupakan hal yang penting, karena dapat mempelajari bagaimana struktur topografi permukaan (asperity) mengalami deformasi (Krisnandi dkk., 2007).

Sistem permesinan akan terdapat kontak antar permukaan part, yaitu kontak yang dapat berupa point contact (kontak titik), surface contact (kontak permukaan), dan line contact (kontak garis). Ketika kontak antar part tersebut dikenakan sebuah gaya mekanik, maka akan timbul suatu fenomena yang disebut sebagai keausan (wear) (Dowson, 1998).

Keausan (wear) adalah hilangnya materi dari permukaan benda padat sebagai akibat dari gerakan mekanik (Kato, 2002). Keausan umumnya sebagai kehilangan materi yang timbul sebagai akibat interaksi mekanik dua permukaan yang bergerak sliding dan dibebani. Ini merupakan fenomena normal yang terjadi jika dua permukaan saling bergesekan, maka akan ada keausan atau perpindahan materi.
Keausan dapat dipengaruhi oleh faktor pembebanan, pelumasan, panjang lintasan, dan sifat dari material tersebut (Besihi dkk., 2010).

Tribologi didefinisikan sebagai ilmu pengetahuan dan teknologi interaksi permukaan dalam gerakan relatif berkaitan dengan fenomena (gesekan dan keausan) yang terkait dengan fisika, mekanika, metalurgi, dan kimia. Di seluruh dunia, keausan dianggap sebagai fenomena kegagalan utama dalam sistem tribologi dan didefinisikan sebagai hilangnya material dari permukaan yang bersinggungan di dalam gerakan relatif dikendalikan oleh sifat material (kekerasan, keuletan, sifat termal, dll), lingkungan (jenis pelumas, suhu), kondisi operasional (topografi permukaan, beban, kecepatan) dan geometri dari permukaan yang bersinggungan (Cracaoanu, 2010).

Pada hampir semua proses dan peralatan mekanik terutama saat komponennya bekerja, terjadi kontak satu sama lain yang dapat berupa kontak statis (static contact), sliding contact, atau rolling contact (Johnson, 2009). Dalam skala besar informasi ini mungkin berguna dalam menganalisis gesekan (friction), keausan (wear), pelumasan (lubrication), dan 
sebagainya. Ilmu mekanika kontak (contact mechanic) merupakan bagian dari ilmu tribologi yang membahas mengenai keausan dua benda yang bersinggungan satu sama lain. Kontak yang terjadi antara dua benda dapat berupa titik (point), garis (line), ataupun elips.

Analisis terhadap gesekan dan keausan dapat dicari menggunakan beberapa metode diantaranya melalui metode penelitian secara eksperimental yaitu dengan cara menguji secara langsung spesimen yang di analisis (Hsu dkk., 2005). Kelebihan dari metode ini diantaranya hasil analisis dapat kita ketahui secara langsung. Berikutnya metode analitik yaitu dengan menganalisis menggunakan pendekatan rumus- rumus matematik. Terakhir yaitu menggunakan metode simulasi dengan bantuan software.

Tribometer adalah perangkat yang digunakan untuk mengukur gesekan dan keausan antara dua permukaan. Alat Tribometer pin-on-disc adalah alat uji gesek dan keausan yang terdiri dari pin dan disc (Rohadi dkk., 2013). Pin memiliki berbagai bentuk dan ukuran, umumnya berbentuk bola atau bentuk silinder batang, sedangkan disc atau piringan dengan tebal tertentu berbentuk plat berdiameter. Penggunaan mesin pin-ondisc biasanya digunakan untuk menguji keausan jenis sliding (Moody, 2007) dan rolling (Taufik dkk., 2018). Metode sederhana ini memfasilitasi peneliti untuk menganalisis tentang gesekan dan keausan menggunakan bermacam jenis material padat dengan mengombinasikan penggunaan pelumas atau tanpa pelumas. Selain itu, kontrol dari parameter uji seperti kecepatan, frekuensi, tekanan kontak, waktu dan parameter lingkungan (suhu, kelembaban dan pelumas) memungkinkan simulasi seperti kondisi nyata.

Sebagai langkah preventif terhadap keausan yang akan terjadi pada komponen, sehingga pada dapat dilakukan pencegahan dari kegagalan komponen karena sebab kerusakan yang diakibatkan keausan permukaan kontak. Adanya perawatan preventif akan menghemat biaya (cost) untuk perawatan maupun efisiensi energi dengan kinerja mesin yang baik. Prediksi umur pakai (life time) dari komponen dapat diperkirakan, serta dapat melakukan pengawasan (controlling) jika terjadi masalah lain yang berkaitan dengan keausan, dari perbandingan perhitungan analitik dan eksperimen akan ditemukan perbedaan, sehingga dapat diketahui kelemahan dan kekurangan dari tribometer pin-on-disc, hal itu dapat menjadi acuan untuk menyempurnakan tribometer pinon-disc pada penelitian selanjutnya. Tujuan penelitian ini adalah untuk mengetahui wear depth (kedalaman aus) serta volume keausan pada pin dengan GIWM dan Archard serta menggunakan metode eksperimen menggunakan tribometer pin-on-disc.

\section{METODOLOGI}

Penelitian ini menggunakan pemodelan Global Incremental Wear Model (GIWM). Tribometer Pin-On-Disc (lihat gambar 2.) digunakan untuk mengetahui tingkat keausan seperti yang pernah dilakukan oleh (Hegadekatte dkk., 2004). Spesimen uji menggunakan steel needle bearing sebagai pin dan steel pada outer ring bearing sebagai disc. Pembahasan fokus pada keausan pin dan mengabaikan keausan pada disc. Pengujian dilakukan tanpa pelumasan dengan menggunakan variasi pembebanan yaitu $6 \mathrm{~N}, 8$ $\mathrm{N}$, dan $10 \mathrm{~N}$. Adapun urutan dari penelitian ini seperti terlihat pada Gambar 1.

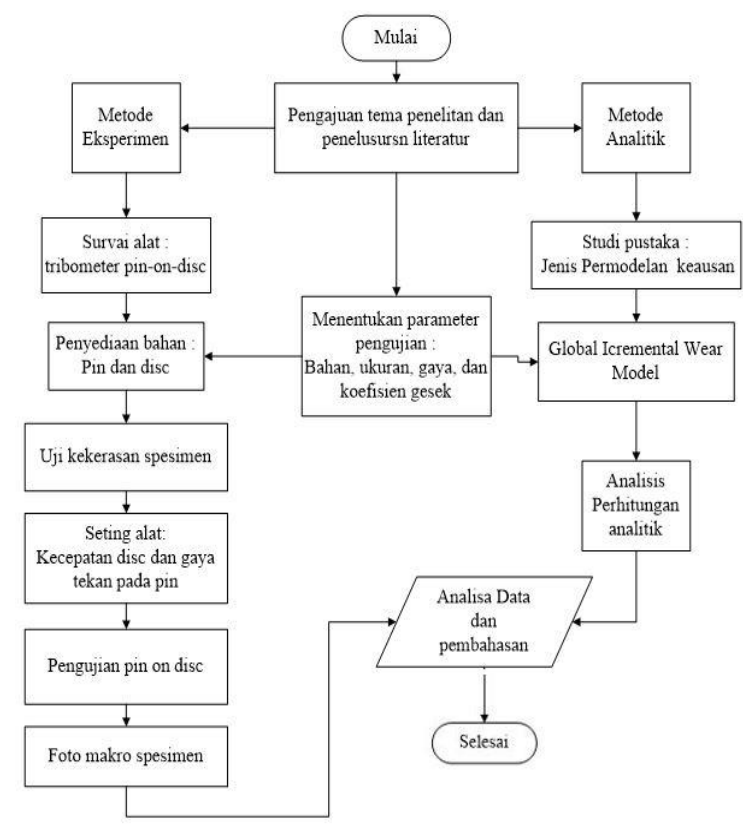

Gambar 1. Diagram Alir Penelitian

Perhitungan analitik GIWM yang dikembangkan oleh (Hegadekatte dkk., 2006) dan (Syafa'at dkk., 2010) (Taufik dkk., 2018), 
untuk volume keausan menggunakan persamaan model (Archard, 1953) dan Van Beek (Beek, 2006). Asumsi yang sama dengan point contact pemodelan pada line contact dikembangkan oleh Syafaat (2010). Pemodelan diambil dari nilai tekanan kontak maksimal dengan mempertimbangkan tekanan kontak rata-rata. Pada perhitungan analitik GIWM berdasarkan Tabel II.1 koefisien gesek yang dipilih adalah $\mathrm{k}_{\mathrm{D}}=1800.10^{-15} \mathrm{~m}^{2} / \mathrm{N}$. Pemilihan nilai koefisien berdasar pada nilai paling dekat dengan hasil eksperimen.

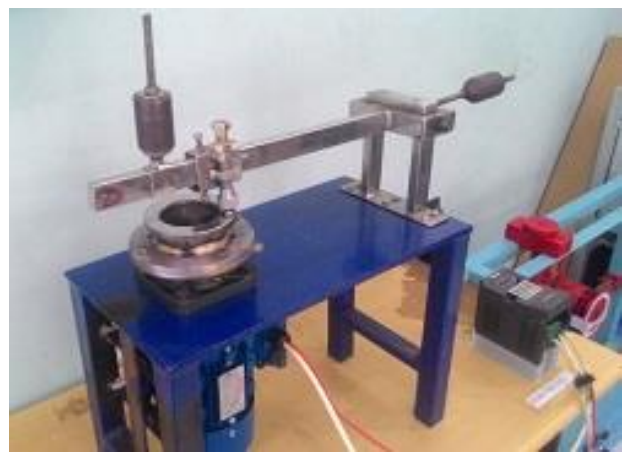

Gambar 2. Tribometer Pin-On-Disc

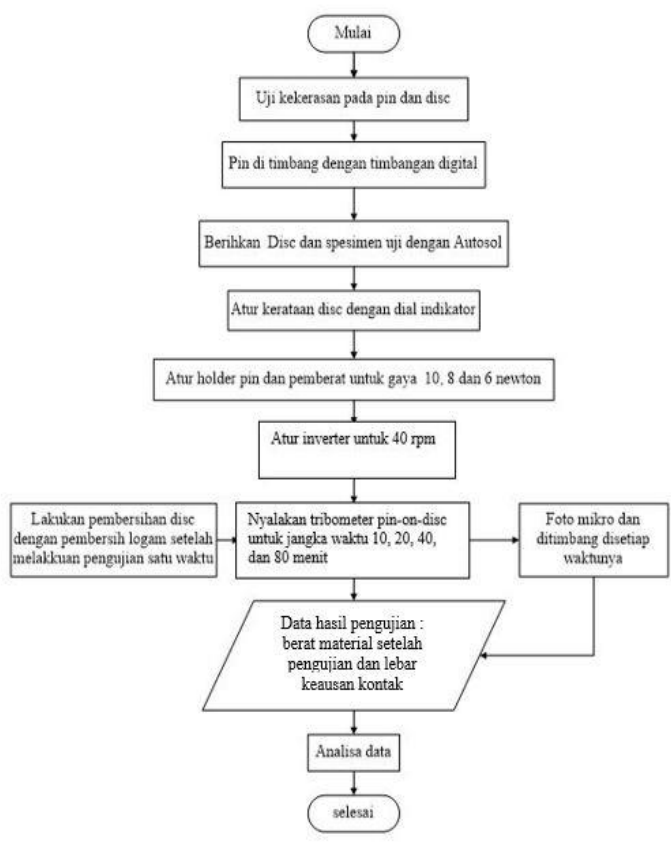

Gambar 3. Diagram Alir Proses Eksperimen

Prosedur dan langkah penelitian meliputi beberapa tahapan seperti pada gambar 3. Pada semua spesimen menggunakan frekuensi 1,33 $\mathrm{Hz}$ pada Inverter. Pada pengujian ini menggunakan tiga spesimen dengan masing - masing diberi pembebanan berbeda yaitu 10, 8, dan $6 \mathrm{~N}$.

\section{HASIL DAN PEMBAHASAN}

Tabel 1. Hasil Perhitungan Analitik GIWM dan Archard

\begin{tabular}{|c|c|c|c|c|}
\hline Spesimen & $\begin{array}{c}\text { Pembebanan } \\
\text { (N) }\end{array}$ & $\begin{array}{c}\text { Jarak } \\
\text { Sliding } \\
\text { (m) }\end{array}$ & $\begin{array}{c}\text { Wear Depth } \\
\text { (GIWM) } \\
\text { (m) }\end{array}$ & $\begin{array}{c}\text { Volume Aus } \\
\text { (Archard) } \\
\left(\mathrm{m}^{3}\right)\end{array}$ \\
\hline \multirow{4}{*}{1} & \multirow{4}{*}{10} & 113,04 & $6,15239 \mathrm{E}-06$ & $2,03472 \mathrm{E}-09$ \\
\hline & & 226,08 & $9,76631 \mathrm{E}-06$ & $4,06944 \mathrm{E}-09$ \\
\hline & & 452,16 & $1,55031 \mathrm{E}-05$ & $8,13888 \mathrm{E}-09$ \\
\hline & & 904,32 & $2,46096 \mathrm{E}-05$ & $1,62778 \mathrm{E}-08$ \\
\hline \multirow{4}{*}{2} & \multirow{4}{*}{8} & 113,04 & $5,30197 \mathrm{E}-06$ & $1,62778 \mathrm{E}-09$ \\
\hline & & 226,08 & $8,41635 \mathrm{E}-06$ & $3,25555 \mathrm{E}-09$ \\
\hline & & 452,16 & $1,33601 \mathrm{E}-05$ & $6,51110 \mathrm{E}-09$ \\
\hline & & 904,32 & $2,12079 \mathrm{E}-05$ & $1,30222 \mathrm{E}-08$ \\
\hline \multirow{4}{*}{3} & \multirow{4}{*}{6} & 113,04 & $4,37668 \mathrm{E}-06$ & $1,22083 \mathrm{E}-09$ \\
\hline & & 226,08 & $6,94755 \mathrm{E}-06$ & $2,44166 \mathrm{E}-09$ \\
\hline & & 452,16 & $1,10285 \mathrm{E}-05$ & $4,88333 \mathrm{E}-09$ \\
\hline & & 904,32 & $1,75067 \mathrm{E}-05$ & $9,76666 \mathrm{E}-09$ \\
\hline
\end{tabular}

Pengujian pin-on-disc menggunakan material seperti dalam tabel 1. sebanyak 3 (tiga) unit pin masing-masing diberi pemberat dengan massa yang berbeda yaitu $10 \mathrm{~N}, 8 \mathrm{~N}$, dan $6 \mathrm{~N}$. Dengan menggunakan inverter berfrekuensi $1,33 \mathrm{~Hz}$ dihasilkan kecepatan 40 RPM pada area kontak pin dan disc. Untuk mencari wear depth menggunakan persamaan Van Beek (II.32) dan volume aus menggunakan persamaan Van Beek (II.29). Dari hasil penimbangan ketiga spesimen antara sebelum pengujian dan sesudah pengujian pada empat waktu pada display timbangan digital tidak mengalami perubahan, artinya timbangan digital yang ada tidak mampu membaca perubahan berat yang terjadi dikarenakan sangat sedikit bagian dari spesimen yang hilang atau aus. Dari tabel 2, pada spesimen 1 dengan pembebanan $10 \mathrm{~N}$ dengan durasi waktu yang sama dengan spesimen 1 dan 2 yang diberi pembebanan $8 \mathrm{~N}$ dan $6 \mathrm{~N}$, spesimen 1 terlihat lebih tinggi untuk nilai rata-rata lebar aus sehingga berpengaruh pada nilai wear depth dan volume aus.

Tabel 2. Hasil Eksperimen Pin-On-Disc 


\begin{tabular}{|c|c|c|c|c|c|c|}
\hline Spesimen & $\begin{array}{l}\text { Pembebanan } \\
\text { (N) }\end{array}$ & $\begin{array}{l}\text { Waktu } \\
\text { (menit) }\end{array}$ & $\begin{array}{c}\text { Jarak } \\
\text { Sliding } \\
\text { (m) } \\
\end{array}$ & $\begin{array}{c}\text { Rata-Rata } \\
\text { Lebar Aus } \\
(\mu \mathrm{m}) \\
\end{array}$ & $\begin{array}{c}\text { Wear Depth } \\
\text { (m) }\end{array}$ & $\begin{array}{c}\text { Volume At } \\
\quad\left(\mathrm{m}^{3}\right) \\
\end{array}$ \\
\hline \multirow{4}{*}{1} & \multirow{4}{*}{10} & 10 & 113,04 & 538,30 & $7,24943 \mathrm{E}-06$ & $1,95118 \mathrm{E}-1$ \\
\hline & & 20 & 226,08 & 694,83 & $1,20844 \mathrm{E}-05$ & $4,19833 \mathrm{E}-1$ \\
\hline & & 40 & 452,16 & 792,83 & $1,57394 \mathrm{E}-05$ & $6,23936 \mathrm{E}-1$ \\
\hline & & 80 & 904,32 & 983,13 & $2,42225 \mathrm{E}-05$ & $1,19069 \mathrm{E}-1$ \\
\hline \multirow{4}{*}{2} & \multirow{4}{*}{8} & 10 & 113,04 & 341,23 & $2,91185 \mathrm{E}-06$ & $4,96811 \mathrm{E}-1$ \\
\hline & & 20 & 226,08 & 542,80 & $7,37123 \mathrm{E}-06$ & $2,00055 \mathrm{E}-1$ \\
\hline & & 40 & 452,16 & 612,63 & $9,39181 \mathrm{E}-06$ & $2,87687 \mathrm{E}-1$ \\
\hline & & 80 & 904,32 & 772,53 & $1,49425 \mathrm{E}-05$ & $5,77179 \mathrm{E}-1$ \\
\hline \multirow{4}{*}{3} & \multirow{4}{*}{6} & 10 & 113,04 & 280,43 & $1,96646 \mathrm{E}-06$ & $2,75730 \mathrm{E}-1$ \\
\hline & & 20 & 226,08 & 369,37 & $3,41196 \mathrm{E}-06$ & $6,30132 \mathrm{E}-1$ \\
\hline & & 40 & 452,16 & 447,10 & $4,99996 \mathrm{E}-06$ & $1,11774 \mathrm{E}-1$ \\
\hline & & 80 & 904,32 & 613,77 & $9,42662 \mathrm{E}-06$ & $2,89287 \mathrm{E}-1$ \\
\hline
\end{tabular}

Pada tiap spesimen dilakukan foto mikro pada menit 10, 20, 40, dan 80 menit. Hasil foto mikro dicontohkan dengan pembebanan $8 \mathrm{~N}$ pada Gambar 4. Spesimen dengan pembebanan $8 \mathrm{~N}$ terlihat pada menit 10 pengujian atau sekitar 113,04 m jarak sliding, rata-rata lebar kontak aus $341,23 \mu \mathrm{m}$ dan terus bertambah seiring waktu hingga pada menit 80 rata-rata lebar kontak aus sebesar $772,53 \mu \mathrm{m}$. Warna kehitaman merupakan material aus yang menempel pada daerah kontak.

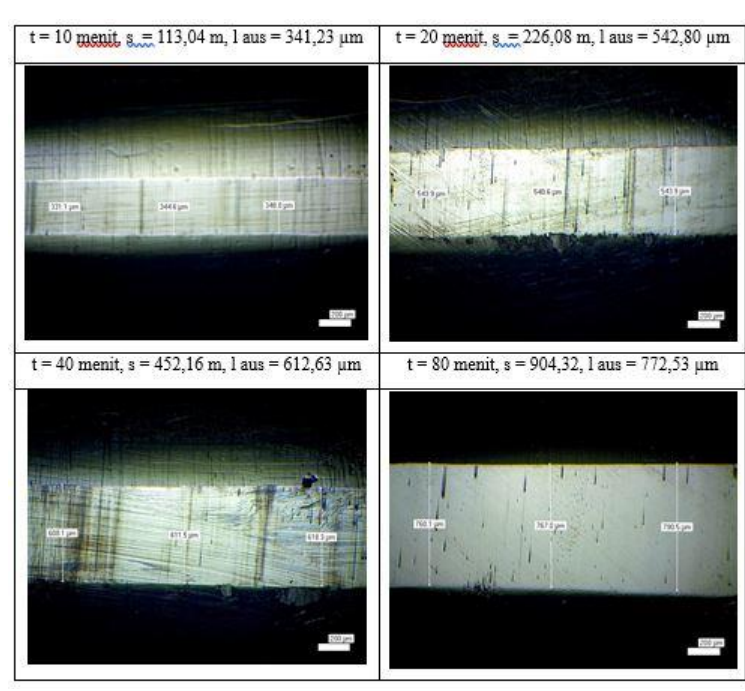

\section{Gambar 4. Foto Mikro pada Spesimen dengan Pembebanan $8 \mathrm{~N}$}

Luas daerah kontak (A) didapatkan dari rumus luas persegi panjang berdasarkan hasil lebar daerah kontak. Gambar 5 menunjukkan pada jarak sliding 113,04 m sampai dengan 904,32 m, luas kontak karena pembebanan 6, 8 , dan $10 \mathrm{~N}$ relatif naik stabil. Hal ini menunjukkan dari awal sampai dengan jarak sliding 904,32 m dalam kondisi daerah kontak stabil.

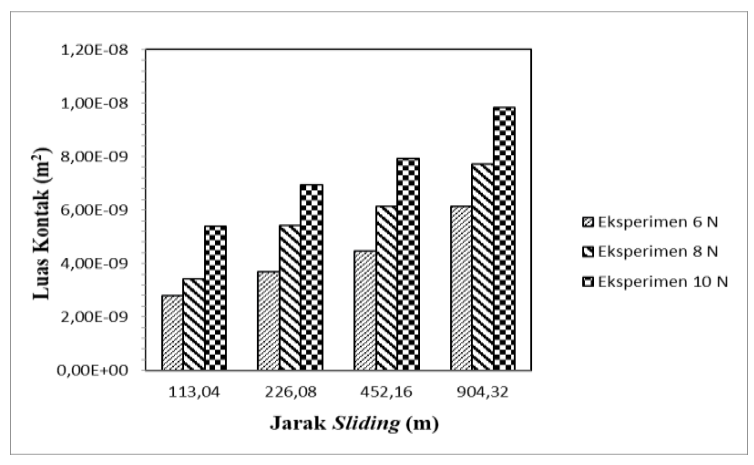

\section{Gambar 5. Luas Daerah Kontak Eksperimen Pin-On-Disc}

Tekanan kontak (P) didapatkan dari gaya normal dibagi luas daerah kontak, seperti terlihat pada Gambar 6. Jarak sliding 113,04 m sampai dengan 904,32 m tekanan kontak terus menurun, pada pembebanan $8 \mathrm{~N}$ mempunyai nilai paling tinggi diikuti pembebanan $6 \mathrm{~N}$, dan pembebanan $10 \mathrm{~N}$ mempunyai tekanan kontak paling rendah. Pada jarak sliding 452,16 m tekanan kontak paling stabil dimana pada pembebanan $6 \mathrm{~N}, 8 \mathrm{~N}$, dan $10 \mathrm{~N}$ ketinggiannya berurutan. Hal ini juga menunjukkan dari awal sampai dengan jarak sliding 904,32 m tekanan kontak dalam kondisi stabil.

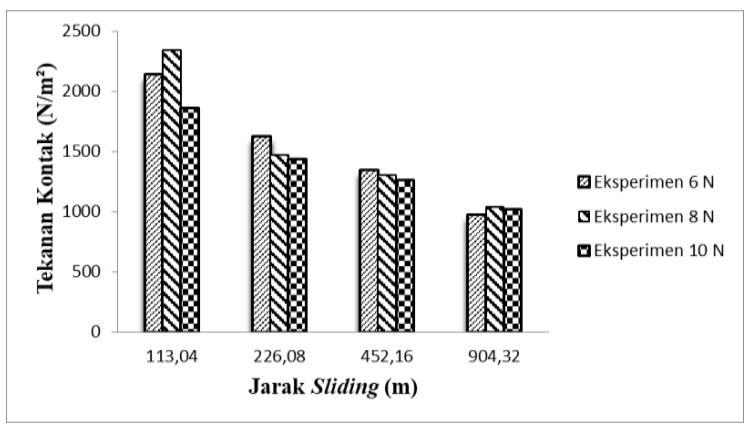

\section{Gambar 6. Tekanan Kontak Eksperimen Pin-On-Disc}

Nilai wear depth hasil plot antara perhitungan analitik GIWM dan eksperimen seperti pada grafik Gambar 7. Untuk pembebanan $10 \mathrm{~N}$ hasil eksperimen hampir mendekati GIWM, pada jarak sliding sekitar 113,04 m, 452,16 m, 904,32 m hasil eksperimen dan GIWM berimpit dan pada jarak sliding 226,08 m nilai eksperimen agak menjauhi GIWM. Pada pembebanan $8 \mathrm{~N}$ hasil eksperimen mempunyai tren menjauh 
berdeviasi 70,30\% pada jarak sliding $452,16 \mathrm{~m}$ dan pada pembebanan $6 \mathrm{~N}$ hasil eksperimen juga mempunyai tren menjauh berdeviasi 49,11\% pada jarak sliding $226,08 \mathrm{~m}$.

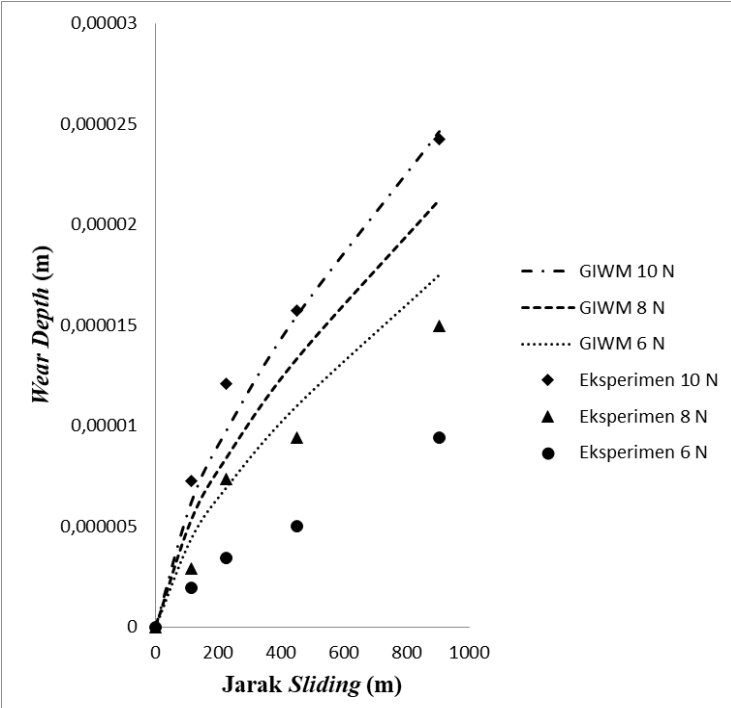

\section{Gambar 7. Wear Depth GIWM dan Eksperimental}

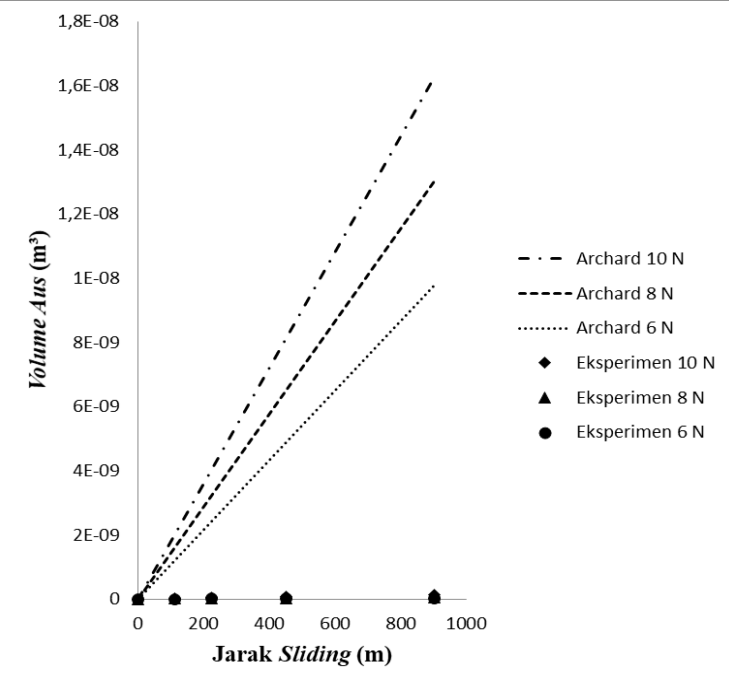

\section{Gambar 8. Grafik Volume Keausan Perbandingan Archard dan Eksperimen}

Nilai volume keausan antara analitik Archard) dengan eksperimen ditunjukkan pada grafik Gambar 8. Pada pembebanan $6 \mathrm{~N}, 8 \mathrm{~N}$, dan $10 \mathrm{~N}$ eksperimen selalu di bawah analitik Archard. Nilai volume keausan pada pembebanan $6 \mathrm{~N}, 8 \mathrm{~N}$, dan $10 \mathrm{~N}$ hasil eksperimen mempunyai tren menjauh analitik.

\section{KESIMPULAN}

Adapun hasil yang diperoleh penulis dalam penelitian ini adalah sebagai berikut :

1. Pada metode analitik GIWM pada pembebanan $10 \mathrm{~N}, 8 \mathrm{~N}$, dan $6 \mathrm{~N}$ pada jarak sliding 904,32 m menghasilkan nilai keausan wear depth $h_{l c}^{w}=2,46096 \mathrm{E}-05 \mathrm{~m}$, $h_{l c}^{w}=2,12079 \mathrm{E}-05 \mathrm{~m}$, dan $h_{l c}^{w}=1,75067 \mathrm{E}-$ $05 \mathrm{~m}$. Nilai wear depth pada pembebanan $10 \mathrm{~N}$ hasil eksperimen hampir mendekati GIWM, pada jarak sliding sekitar 113,04 m, 452,16 m, 904,32 m hasil eksperimen dan GIWM berimpit dan pada jarak sliding 226,08 m nilai eksperimen agak menjauhi GIWM. Pada pembebanan $8 \mathrm{~N}$ hasil eksperimen mempunyai tren menjauh berdeviasi $70,30 \%$ pada jarak sliding $452,16 \mathrm{~m}$ dan pada pembebanan $6 \mathrm{~N}$ hasil eksperimen juga mempunyai tren menjauh berdeviasi $49,11 \%$ pada jarak sliding 226,08 m.

2. Pada metode analitik Archard, nilai volume keausan pada jarak sekitar 904,32 m pada pembebanan $10 \mathrm{~N}, \mathrm{v}=1,62778 \mathrm{E}-08 \mathrm{~m}^{3}$. Pada pembebanan $8 \mathrm{~N}$ dan $6 \mathrm{~N}$ volume keausan yang dihasilkan $\mathrm{v}=1,30222 \mathrm{E}-08$ $\mathrm{m}^{3}$ dan 9,76666E-09 $\mathrm{m}^{3}$. Pada metode eksperimen dengan pembebanan $10 \mathrm{~N}$ pada jarak sliding yang sama pada pembebanan $10 \mathrm{~N}, \quad \mathrm{v}=1,19069 \mathrm{E}-10 \mathrm{~m}^{3}$. Pada pembebanan $8 \mathrm{~N}$ dan $6 \mathrm{~N}$ volume keausan yang dihasilkan $\mathrm{v}=5,77179 \mathrm{E}-11 \mathrm{~m}^{3}$ dan 2,89287E- $11 \mathrm{~m}^{3}$. Pada pembebanan $6 \mathrm{~N}, 8$ $\mathrm{N}$, dan $10 \mathrm{~N}$ eksperimen selalu di bawah analitik Archard. Nilai volume keausan pada pembebanan $6 \mathrm{~N}, 8 \mathrm{~N}$, dan $10 \mathrm{~N}$ hasil eksperimen mempunyai tren menjauh analitik.

\section{DAFTAR PUSTAKA}

Archard, J. F. (1953). Contact and rubbing of flat surfaces. Journal of applied physics. https://doi.org/10.1063/1.1721448

Beek, A. Van. (2006). Advanced engineering design: lifetime performance and reliability (Vol. 1).

Besihi, N. A., Darmanto, \& Syafa'at, I. (2010). Analisis Keausan Baja ST60 Menggunakan Alat Tribotester Tipe Pin On Disc dengan Variasi Kondisi Pelumas. 9(2), 5-9.

Cracaoanu, I. (2010). Effect of macroscopic 
wear on friction in lubricated concentrated contacts. research.utwente.nl.

https://research.utwente.nl/en/publicatio ns/effect-of-macroscopic-wear-on-

friction-in-lubricated-concentrated-2

Dowson, D. (1998). History of tribology. Number. ... London and Bury St Edmunds, UK.

Hegadekatte, V., Huber, N., \& ... (2006). Modeling and simulation of wear in a pin on disc tribometer. International Joint .... https://asmedigitalcollection.asme.org/IJ TC/proceedingsabstract/IJTC2006/42592a/567/318515

Hegadekatte, V., Huber, N., \& Kraft, O. (2004). Finite element based simulation of dry sliding wear. Modelling and Simulation in https://doi.org/10.1088/09650393/13/1/005

Hsu, S. M., Shen, M. C., \& Stachowiak, G. (2005). Wear mapping of materials. Wear-Materials, Mechanisms https://books.google.com/books?hl=en\& lr=\&id=DBR75HUkYhEC\&oi=fnd\&pg $=$ PA369\&dq $=$ wear + mapping + of + materi als\&ots $=99$ mobNU9Wz\&sig $=U f R d j p i E$ MlCZffaw3J1d33oKrLg

Johnson, K. L. (2009). Contact mechanics. Proceedings of the Institution of Mechanical https://search.proquest.com/openview/35 6a5d7e39e9fa8dd1ebac37914f50c0/1?pq -origsite $=$ gscholar $\& \mathrm{cbl}=30473$

Kato, K. (2002). Classification of wear mechanisms/models. ... of the Institution of Mechanical Engineers, Part $J$... https://doi.org/10.1243/13506500276235 5280

Krisnandi, D. D., Burhanudin, A., Armanto, E., Prabowo, D., Sulardjaka, \& Jamari. (2007). Studi Eksperimental Pengaruh Beban Terhadap Koefisien Gesek Pada Sliding Contact Fase Running-In dengan Tribometer Pin-On-Disc. 18-22.

Moody, J. J. (2007). A finite element analysis of elastic-plastic sliding of hemispherical contacts. smartech.gatech.edu. https://smartech.gatech.edu/handle/1853/ 31992

Rohadi, A., Darmanto, D., \& ... (2013). Analisis Keausan Baja St. 40
Menggunakan Tribotester Pin-On-Disc Dengan Variasi Kondisi Pelumas. Jurnal Ilmiah

https://publikasiilmiah.unwahas.ac.id/ind ex.php/MOMENTUM/article/view/926

Syafa'at, I., Widyanto, S. A., \& Jamari, J. (2010). Pemodelan Keausan Steady State.

http://eprints.undip.ac.id/25497/1/Pemod elan_Keausan_Steady_State\%2C_Imam _Syafaat_-_MTM_Undip_-_2010.pdf

Taufik, A., Darmanto, \& Imam Syafa'at. (2018). Analisis Keausan Kampas Rem pada Disk Break dengan Variasi Kecepatan. 